\title{
Artistic creativity and risk for schizophrenia, bipolar disorder and unipolar depression: a swedish population-based case-control study and sib-pair analysis
}

J. H. MacCabe, A. Sariaslan, C. Almqvist, P. Lichtenstein, H. Larsson and S. Kyaga

\section{Background}

Many studies have addressed the question of whether mental disorder is associated with creativity, but high-quality epidemiological evidence has been lacking.

\section{Aims}

To test for an association between studying a creative subject at high school or university and later mental disorder

\section{Method}

In a case-control study using linked population-based registries in Sweden $(N=4454763)$, we tested for associations between tertiary education in an artistic field and hospital admission with schizophrenia $(N=20333)$, bipolar disorder $(N=28293)$ or unipolar depression $(N=148365)$.

\section{Results}

Compared with the general population, individuals with an artistic education had increased odds of developing schizophrenia (odds ratio $=1.90,95 \% \mathrm{Cl}=[1.69 ; 2.12]$ ) bipolar disorder (odds ratio $=1.62[1.50 ; 1.75]$ ) and unipolar depression (odds ratio $=$ $1.39[1.34 ; 1.44]$. The results remained after adjustment for IQ and other potential confounders

\section{Conclusions}

Students of artistic subjects at university are at increased risk of developing schizophrenia, bipolar disorder and unipolar depression in adulthood.

\section{Declaration of interest}

None.

\section{Copyright and usage}

(c) The Royal College of Psychiatrists 2018.

\section{Background}

The notion that mental disorders are associated with enhanced creativity, intelligence or artistic talent is one of the oldest in psychiatry. Some of the most influential research in this area was based on retrospective reviews drawn from biographical sources ${ }^{1}$ and small casecontrol studies of people in creative professions. ${ }^{2}$ These studies had selection and information bias as well as low statistical power. Thus, reviewing the literature in 2011, Hurlow and MacCabe ${ }^{3}$ concluded that there was no convincing evidence of an association and that large scale, population-based studies were required. Kyaga and colleagues ${ }^{4}$ conducted a population-based study, using data from Swedish national registers, that demonstrated that people with bipolar disorder and their healthy relatives were over-represented in artistic and scientific occupations. The healthy relatives of people with schizophrenia were also over-represented in such occupations, but those people with schizophrenia were not; although this latter finding must be interpreted cautiously because of the low rates of employment in the schizophrenia group. ${ }^{4}$ In a separate Swedish population study, MacCabe and colleagues ${ }^{5}$ showed that excellent school performance at age 16 was associated with an increased risk of later bipolar disorder, but was protective against schizophrenia and other psychoses; ${ }^{6}$ a systematic review showed similar findings. ${ }^{7}$ This raises questions about the overlap between creativity, educational attainment and intelligence, which (if any) of these markers has the strongest association with which mental disorders, and to what extend they confound one another. Recently, Power et al found evidence for a genetic association between creativity and mental disorder by showing, in the Icelandic population, that polygenetic risk scores for schizophrenia and bipolar disorder are associated with creative occupations. Taken together, these results support the hypothesis that some aspects of intelligence and/or creativity may be associated with bipolar disorder and possibly also schizophrenia, and that this association may be at least partly driven by genetics.

\section{Aims}

In this study, we sought to test the hypothesis that creativity is associated with severe adult mental disorders in a national population. Our study incorporates five innovations. First, we used a new proxy of creativity: studying a creative or artistic subject at university or upper secondary school. Unlike artistic occupations, artistic study predates the illness in many cases, reducing the probability that any association might arise through reverse causation. Second, although some very accomplished scientific leaders could be described as creative, it is likely that many scientific graduates have a more logical or analytical cognitive style. Furthermore, most prior evidence of an association with mental disorder has been with artistic creativity. We therefore chose to focus on artistic, rather than scientific, creativity. Third, because the relationship between creativity, educational attainment and IQ is difficult to disentangle, we obtained measures of all three to assess the extent to which they confound one another. Fourth, we took into account shared familial factors in a sub-analysis restricted to pairs of siblings discordant for creative study. Fifth, we conducted sensitivity analyses to test the specificity of both the exposure and the outcome.

\section{Method}

\section{Study design}

The study employed a case-control design using population registers covering the whole population of Sweden. We compiled the data set by linking data from the following registers, via the unique registration number carried by all Swedish residents. 


\section{LISA database}

This database holds annual registers from 1990 to 2009 and includes all individuals aged 16 years and older that were residing in Sweden on 1 November of the previous year. This database provided demographic information including the gender and date of birth of the participants.

\section{Higher education register}

Information on level and subject of study at upper secondary school and university, coded according to the Swedish educational nomenclature (SUN). SUN is a standard for classification of individual educational programs, while also allowing aggregation of programs to larger groups. ${ }^{9}$ It was created in the late 1960 s, and revised in 1998-1999 (SUN 2000) to align with the International Standard Classification of Education 1997.

\section{Military service conscription register}

Military conscription was compulsory for men at age 18 until 2009, although a small number of individuals were excused conscription on grounds of ill health, including intellectual disability. As part of their assessment, the conscripts underwent intelligence testing. The test used written questionnaires from 1969 to 1994 and was computer based thereafter. Both tests assessed four aspects of intelligence (logical/inductive, verbal, spatial/visual and theoretical/ technical reasoning) and included 160 questions (40 for each dimension). ${ }^{10}$ The results were standardised against the entire population.

\section{Multigenerational register}

This register, which links individuals to their first-degree relatives, allowed the identification of sib pairs within the population who were registered as living in Sweden after 1960.

\section{National patient register}

This contains details on virtually all psychiatric hospitalisations since 1973, including admission and discharge dates and the discharge diagnosis made by the treating physician. It contains outpatient contacts with specialist physicians including psychiatrists from 2001. It is coded using the ICD-8 (1969-1986), ICD-9 (1987-1996) and subsequently ICD-10. ${ }^{11}$

\section{Sample and caseness definitions}

The sample comprised all individuals in the LISA database aged 20-64 on 31 December 2009. To avoid the possibility of confounding by migration status, which is associated with both schizophrenia ${ }^{12}$ and educational level, ${ }^{13}$ we excluded individuals who were born outside Sweden. We also excluded individuals with missing data on the educational level.

Cases were defined as all individuals hospitalised with a register diagnosis of schizophrenia, bipolar disorder or unipolar depression from 1 January 1973 to 31 December 2009. These disorders were defined according to the Swedish version of the ICD-8, -9 and -10 , using the following codes. For bipolar disorder: ICD-8: 296 (excluding 296.2); ICD-9: 296 (excluding 296B); ICD-10: F30-31. For schizophrenia: ICD-8 and -9: 295; ICD-10: F20. For unipolar depression: ICD-8: 296.2, 300.4; ICD-9: 296B, 300E, 311; ICD-10: F32-24 (excluding F32.3), F38-39. A hierarchical diagnostic system was used such that if more than one diagnosis was present in any given individual, schizophrenia took precedence over bipolar disorder, which in turn took precedence over unipolar depression. For each analysis, with the exception of the sib-pair analysis, the remainder of the population constituted the control group.

\section{Definition of creative subject}

The exposure was defined as having completed a course of study in an artistically creative subject at university or gymnasieskola (upper secondary school).

We used two definitions of artistic creativity: a broad definition which included a wider variety of creative or artistic subjects corresponding to 'Art and Media' in the SUN 2000 definition, but excluding 'Science and History of Art, Music, Dance, Film and Theatre'; and a narrow definition, comprising visual arts, music, dance, theatre and drama, film, radio and TV production, and fashion design. To test the specificity of the associations to particular fields of artistic study, we defined two further sub-specialisations: visual arts, and performing arts. The university subjects corresponding to the four definitions of creative subjects are listed in Table 1.

Table 1 Classification of artistic subjects, showing wide and narrow definitions of creativity and definitions of visual and performing arts

\begin{tabular}{|c|c|c|c|c|c|}
\hline & Course & $\begin{array}{l}\text { Wide definition of artistic } \\
\text { creativity }\end{array}$ & $\begin{array}{l}\text { Narrow definition of } \\
\text { artistic creativity }\end{array}$ & $\begin{array}{l}\text { Visual } \\
\text { Arts }\end{array}$ & Performing Arts \\
\hline $\begin{array}{l}\text { Arts and media, general } \\
\text { education }\end{array}$ & Arts and media, general education & $\mathbf{x}$ & & & \\
\hline \multirow[t]{3}{*}{ Visual arts } & Visual arts & $\mathbf{x}$ & $\mathbf{x}$ & $\mathbf{x}$ & \\
\hline & Science and history of arts & & & & \\
\hline & Other courses in area & $\mathbf{x}$ & & & \\
\hline \multirow{3}{*}{ Music, dance and drama } & Music & $\mathbf{x}$ & $\mathbf{x}$ & & $\mathbf{x}$ \\
\hline & Dance, theatre and drama & $\mathbf{x}$ & $\mathbf{x}$ & & $\mathbf{x}$ \\
\hline & Other courses in area & $\mathbf{x}$ & & & \\
\hline \multirow[t]{5}{*}{ Media production } & Media production, general education & $\mathbf{x}$ & & & \\
\hline & Film, radio and TV production & $\mathbf{x}$ & $\mathbf{x}$ & & \\
\hline & Graphic arts technology and bookbinding & $\mathbf{x}$ & & & \\
\hline & $\begin{array}{l}\text { Illustration, advertisement, graphic design } \\
\text { and photography }\end{array}$ & $\mathbf{x}$ & & & \\
\hline & Other courses in area & $\mathrm{x}$ & & & \\
\hline \multirow[t]{4}{*}{ Design } & Fashion design & $\mathbf{x}$ & $\mathbf{x}$ & & \\
\hline & Interior design & $\mathbf{x}$ & & & \\
\hline & Industrial and product design & $\mathbf{x}$ & & & \\
\hline & Other courses in area & $\mathbf{x}$ & & & \\
\hline Handicraft & Handicraft & $\mathbf{x}$ & & & \\
\hline $\begin{array}{l}\text { Arts and media, other/ } \\
\text { unspecified }\end{array}$ & Arts and media, other/unspecified & $x$ & & & \\
\hline
\end{tabular}




\section{Statistical analysis}

We conducted all analyses using Stata/IC version 12. For each combination of exposure and outcome, we performed logistical regression and calculated odds ratios with $95 \%$ confidence intervals, adjusting for age and gender. To adjust for the possible effects of university attendance per se, we performed a second analysis adjusted for age, gender and highest educational level achieved. In males only, we performed an additional analysis adjusting for IQ at age 18-19. Lastly, to control for familial factors, we conducted a sibling-pair analysis in which we compared the odds of developing mental disorder in sibling pairs discordant for the exposure, adjusting for age, gender and highest educational level achieved.

To detect any unsuspected sources of bias, we conducted sensitivity analyses using a 'negative control' exposure and outcome. Negative control exposures are exposures not expected to be associated with the outcome of interest, whereas negative control outcomes are outcomes not expected to be associated with the exposure of interest. Substituting in the negative control variables is designed to detect confounding and bias in observational studies. The rationale underlying this approach is that if the associations between the exposure and outcome of interest had arisen through inherent biases in the study design, undetected confounding, or other spurious mechanisms; one would expect these associations to also be present when substituting the negative control exposures and outcomes for the exposures and outcomes of interest. ${ }^{14}$

We selected a negative exposure (studying for a law degree) and a negative outcome (diabetes, ICD-8/-9: 250; ICD-10: E10-14) on the basis that they had no known or suspected aetiological associations, but had similar prevalences, to the exposures and outcomes of interest. Using analyses that were identical to the main analysis described above, we then tested for associations between studying law and developing the mental disorders of interest, and between studying artistically creative subjects and developing diabetes.

\section{Results}

In the LISA database there were 5462466 individuals aged 20-64 on 31 December 2009. Approximately 1 million of these were excluded as they were born outside Sweden, reducing the total sample to 4474662 . A further 19899 people were excluded as they had no data on educational level, bringing the total sample to 4454763 .

\section{Prevalence of exposures and outcomes}

A total of 194039 individuals (4.36\%) met the broad criterion off having studied an artistically creative subject, and 50288 individuals (1.13\%) met the narrow criteria. There were 50933 individuals (1.14\%) that had studied the negative control subject of law and jurisprudence. Of the 194039 people who had an artistic education (broad definition), 147477 had a sibling discordant for artistic education. The sib-pair analysis therefore included 294954 individuals.

A total of 28293 individuals $(0.64 \%)$ were diagnosed with bipolar disorder, 20333 individuals $(0.46 \%)$ were diagnosed with schizophrenia and 148365 individuals (3.33\%) were diagnosed with unipolar depression. There were 94363 individuals (2.12\%) that were diagnosed with diabetes.

\section{Demographic characteristics of the sample}

The demographic characteristics of the sample are presented in Table 2.

\section{Association between artistically creative subject and mental disorder}

Table 3 shows the associations between studying an artistically creative subject and the occurrence of mental disorders. In model I, we present the associations in the entire sample, adjusted for year of birth and gender. We found a moderate association between studying broadly defined artistic subjects and risk for bipolar disorder and

\begin{tabular}{|c|c|c|c|c|c|}
\hline & Whole sample & Bipolar & Schizophrenia & Depression & Diabetes \\
\hline$N(\%)$ & 4454763 (100.00\%) & $28293(0.64 \%)$ & $20333(0.46 \%)$ & $148365(3.33 \%)$ & $94363(2.12 \%)$ \\
\hline Mean age on 31 December 2009 (s.d.) & $42.31(13.06)$ & $44.76(12.44)$ & $48.68(10.30)$ & $42.96(13.17)$ & $50.96(11.80)$ \\
\hline Age at first hospitalisation & Not applicable & $36.48(11.80)$ & $32.07(10.14)$ & 35.91 (12.59) & $40.27(16.51)$ \\
\hline Male $(n)$ & $2275400(51.08 \%)$ & 11089 (39.19\%) & $12363(60.80 \%)$ & $57770(38.94 \%)$ & $56384(59.75 \%)$ \\
\hline \multicolumn{6}{|l|}{ Highest educational level } \\
\hline Primary (to approximately age 16) & 583924 (13.11\%) & $5236(18.51 \%)$ & $6688(32.89 \%)$ & $29510(19.89 \%)$ & $21627(22.92 \%)$ \\
\hline Secondary (to approximately age 18-19) & $2943813(66.08 \%)$ & $18148(64.14 \%)$ & $11994(58.99 \%)$ & 95347 (64.27\%) & 60579 (64.20\%) \\
\hline Tertiary & $927026(20.81 \%)$ & 4909 (17.35\%) & 1651 (8.12\%) & $23508(15.84 \%)$ & $12157(12.88 \%)$ \\
\hline $\begin{array}{l}\text { Mean stanine score in cognitive assessment at age } 18 \text { (males } \\
\text { only) (s.d.) }\end{array}$ & $5.13(1.93)$ & $4.83(2.00)$ & $4.10(2.06)$ & 4.67 (1.98) & 4.75 (1.99) \\
\hline
\end{tabular}

Table 3 Odds ratios and 95\% confidence intervals for associations between wide and narrow definitions of artistic education and psychiatric disorders with diabetes as a negative control

\begin{tabular}{|c|c|c|c|c|c|c|}
\hline & \multicolumn{3}{|c|}{ Wide definition of artistic education } & \multicolumn{3}{|c|}{ Narrow definition of artistic education } \\
\hline & Model $\mathrm{I}^{\mathrm{a}}$ & Model II ${ }^{\mathrm{b}}$ & Model III ${ }^{\mathrm{C}}$ & Model I ${ }^{a}$ & Model II & Model III ${ }^{\mathrm{C}}$ \\
\hline & OR $[95 \% \mathrm{Cl}]$ & OR $[95 \% \mathrm{Cl}]$ & OR $[95 \% \mathrm{Cl}]$ & OR $[95 \% \mathrm{Cl}]$ & OR $[95 \% \mathrm{Cl}]$ & OR $[95 \% \mathrm{Cl}]$ \\
\hline Bipolar disorder & $1.29[1.22 ; 1.36]$ & $1.35[1.27 ; 1.42]$ & $1.26[1.15 ; 1.39]$ & $1.53[1.42 ; 1.66]$ & $1.62[1.50 ; 1.75]$ & $1.30[1.13 ; 1.49]$ \\
\hline Schizophrenia & $1.09[1.00 ; 1.19]$ & $1.30[1.19 ; 1.42]$ & $1.19[1.02 ; 1.37]$ & $1.50[1.34 ; 1.68]$ & $1.90[1.69 ; 2.12]$ & $1.56[1.27 ; 1.90]$ \\
\hline Unipolar depression & $1.22[1.19 ; 1.25]$ & $1.29[1.26 ; 1.32]$ & $1.20[1.15 ; 1.25]$ & $1.29[1.24 ; 1.34]$ & $1.39[1.34 ; 1.44]$ & $1.21[1.13 ; 1.28]$ \\
\hline Diabetes & $0.97[0.92 ; 1.01]$ & $1.04[0.99 ; 1.09]$ & $1.07[0.99 ; 1.16]$ & $0.88[0.82 ; 0.95]$ & $0.99[0.92 ; 1.06]$ & $1.09[0.96 ; 1.23]$ \\
\hline
\end{tabular}


unipolar depression. The association with schizophrenia was of borderline significance. The associations for all three disorders became stronger when we used the narrower definition of artistic subjects.

In model II, we additionally adjusted for highest educational level to control for confounding by university attendance. All the associations remained; indeed, the odds ratios became somewhat stronger.

In model III, we adjusted for familial factors by comparing sib pairs within families (adjusting for age, gender and highest educational level). All the associations were somewhat attenuated, suggesting some confounding by familial factors.

\section{Subtypes of artistically creative subjects}

To test the hypotheses regarding associations of specific subtypes of artistic field with mental disorders, we tested for associations with visual arts and performing arts. Visual arts had consistently stronger associations with all mental health outcomes than performing arts (Table 4).

\section{Negative controls}

Diabetes had no associations with studying an artistic subject in any of the models tested, other than the narrow definition of artistic education, which showed a small protective effect against diabetes in model I (Table 3). Law and jurisprudence appeared protective against all three mental disorders in the crude analysis (model I) but these associations were abolished for bipolar disorder and schizophrenia after adjusting for educational level (model II) and in the sib-pair analysis (model III) (Table 4), suggesting that they arose through confounding.

\section{Models adjusted for intelligence (males only)}

In males only ( $N=1680414)$, we were able to adjust for intelligence at age 18 from the conscript register. Adjustment for intelligence had a negligible effect on the estimates (Table 5).

\section{Discussion}

In this population-based case-control study and sibling-pair analysis, we have demonstrated an association between studying an artistically creative subject and hospitalisation for schizophrenia, bipolar disorder and unipolar depression. The associations remain when the analyses are restricted to sibling pairs, indicating that family-level factors alone cannot explain the association.

There is some evidence that the association with mental illness was strongest for core creative subjects, especially for visual arts. It is notable that, in the visual arts, most if not all practitioners are engaged in the creative process, whereas performing arts place more emphasis on interpretation. Hence, the core creative subjects, particularly visual arts, may capture the concept of creativity most closely, supporting the idea that mental disorder is associated with creativity per se.

These findings build on those of Kyaga et al. ${ }^{4}$ In that study, creative occupation was used as a marker of creativity. Only bipolar disorder was associated with creative occupation, with no association seen for schizophrenia or depression. The first degree relatives of people with both bipolar disorder and schizophrenia, but not unipolar depression, were more likely to hold creative occupations. The low rates of employment for people with schizophrenia may explain the lack of association between creative occupation and schizophrenia in that study. In the present study, by contrast, studying an artistic subject was associated with increased risks for all three disorders.

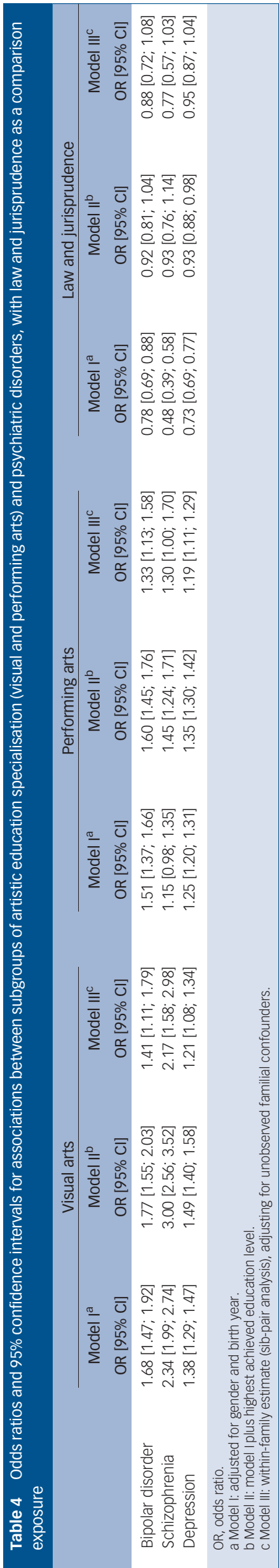


$\bar{\sigma} \bar{m}$

m N

غें

\section{Limitations}

\section{Definition of exposure and comparability with previous studies}

The concept of creativity is a nebulous one: in one commonly used definition, it is the capacity to produce new or original ideas, insights, inventions, or artistic products, which are accepted by experts as being of scientific, aesthetic, social, or technical value'. ${ }^{15}$ Capturing such a concept at the population level using routinely collected data is not straightforward. Much of the early work in this field ${ }^{1,2,16}$ focused on individuals who had achieved outstanding success or esteem in their fields, or had been unusually productive. Our exposure, studying an artistic subject, may not capture the attributes of originality or external endorsement that are often seen as central to creativity. However, the decision to study a creative subject implies a disposition to creative pursuits, and it is likely that people choosing a creative subject will have higher than average levels of innate creative ability.

Other studies have used occupation as a proxy for creativity, but this has its own drawbacks. Since psychosis has a peak onset in the third decade, most people with psychosis do not have an opportunity to establish a career and those who do will be biased towards later onset, more transient or less severe cases of psychosis. A further difficulty is that many people pursuing creative lifestyles may not hold occupations that are recognisably creative; for example, they may be listed in registers as self-employed or unemployed. We therefore argue that the study of a creative subject is likely to capture intrinsic creativity and usually pre-dates the onset of psychosis.

\section{Reverse causation}

Using occupation as the exposure is problematic because the career choices of people with mental disorders may be influenced by the disorder itself; for example, art or music may be used as a form of therapy, or an artistic lifestyle may be more compatible with chronic mental illness than a conventional 'nine-to-five' job. Given that the mean age at first hospitalisation ranged between 32-36 years (Table 2 ) and that university courses are typically completed several years earlier, it is likely that scholarship in an artistic field preceded the diagnosis of mental disorder in the majority of cases. However, the possibility remains that subclinical psychotic symptoms or abnormal mood states may have influenced the decision to pursue artistic studies.

\section{Confounding}

We found no evidence of confounding by age, gender, educational attainment or IQ. There was only weak evidence of confounding by family-level factors. It remains possible that other unmeasured factors are confounding the association. One possible confounder is drug misuse, which is associated with psychosis ${ }^{17}$ and which may also be linked to creativity. ${ }^{18}$ However, in a previous study in Sweden, people in overall creative professions were shown to have reduced rates of alcohol and drug misuse, ${ }^{19}$ making this explanation unlikely.

Bias

One of the primary strengths of Swedish population-based studies is the almost total population coverage, with minimal selection bias. ${ }^{12}$ If the findings had resulted from any biases inherent to the study design, we would have likely seen associations with the negative exposure (law) and the negative outcome (diabetes), so the absence of any such associations is reassuring.

An established limitation of the sibling-comparison approach is that it increases measurement error, which generally attenuates the effect sizes. ${ }^{20}$ The fact that there is little attenuation compared with the population estimates is evidence of robust associations. 


\section{Putative explanations for the association}

\section{At the population level: evolutionary genetics}

People with psychosis have fewer offspring than the general population $^{21,22}$ and this reduced fertility is detectable at illness onset. ${ }^{23}$ The 'balancing selection' hypothesis holds that the genetic variants conferring risk for psychosis also carry a biological advantage, such as enhanced intelligence or creativity, and this translates into reproductive advantage in the relatives of those with psychoses; thus maintaining the frequency of risk alleles in the population. ${ }^{24}$

However, several recent findings have largely obviated the need for such explanations. First, there is emerging evidence that much of the genetic susceptibility to psychosis arises through de novo or very recent mutations. ${ }^{25}$ Second, the common variants associated with schizophrenia are much more numerous and of smaller effect than was previously thought, with likely interactions with environmental risk factors, so the selection pressure against these variants is likely to be minimal. ${ }^{26}$ Third, although schizophrenia is consistently associated with reduced fertility, this is not the case for affective psychoses. ${ }^{21,22}$ A fourth consideration is that there is, as yet, no convincing evidence that creativity is actually associated with any reproductive advantage.

Nevertheless, a recent finding has breathed new life into the balancing selection hypothesis. Power and colleagues ${ }^{8}$ demonstrated that polygenic risk scores for schizophrenia and bipolar disorder were associated with membership of artistic societies or creative professions in Iceland, and they replicated this finding in combined samples from the Netherlands and Sweden, indicating that the association between creativity and psychosis was likely driven by genetic factors.

\section{At the individual level: psychological explanations}

Psychological theories propose that certain cognitive styles may be associated with artistic creativity and psychosis. Divergent thinking patterns, in which inventive and original links are forged between ideas, may be central to creative thinking, ${ }^{27,28}$ whereas in other circumstances they could give rise to thought disorder or delusion formation.

\section{Clinical implications and future research directions}

These data appear to show associations between artistic creativity and risks of severe mental illness that are of comparable magnitude to several established risk factors for psychotic disorders. This may have implications for service provision; for example, awareness of this association could be raised in university settings and occupational health and counselling services. It also raises the question of how arts and other creative activities might be used therapeutically. An important goal for future research will be to improve our understanding of what genetic or environmental factors might be important in launching a genetically predisposed individual on a trajectory of productive creativity rather than mental illness.

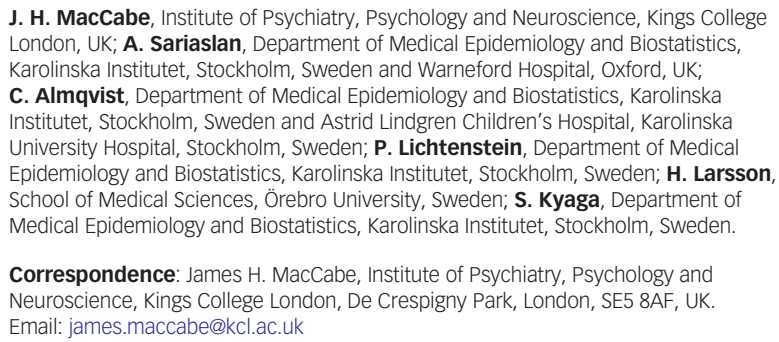

First received 23 May 2017, final revision 9 Nov 2017, accepted 22 Jan 2018

\section{Funding}

This work was funded from an Independent Investigator Award to J.H.M. from the Brain and Behaviour Research Foundation (formerly National Alliance for Research on Schizophrenia and Depression). J.H.M. is also supported by the Biomedical Research Centre for Mental Health at the Institute of Psychiatry, Psychology and Neuroscience and the South London and Maudsley National Health Service Foundation Trust. We acknowledge financial support from the Swedish Research Council through the Swedish Initiative for Research on Microdata in the Social and Medical Sciences framework, grant number 340-2013-5867 (princition, management, analysis, interpretation of the data, nor in the preparation, review or approval of the manuscript.

\section{Acknowledgements}

A.S. had full access to all the data in the study and takes responsibility for the integrity of the data and the accuracy of the data analysis.

\section{References}

1 Jamison KR. Mood disorders and patterns of creativity in British writers and artists. Psychiatry 1989; 52: 125-34.

2 Andreasen NC. Creativity and mental illness: prevalence rates in writers and their first-degree relatives. Am J Psychiatry 1987; 144: 1288-92.

3 Hurlow J, MacCabe JH. Paradoxes in creativity and psychiatric conditions. In The Paradoxical Brain (eds N Kapur, A Pascual-Leone, V Ramachandren, J Cole, S Della Sala, T Manly, et al.): 289-300. Cambridge University Press, 2011.

4 Kyaga S, Lichtenstein P, Boman M, Hultman C, Långström N, Landén M. Creativity and mental disorder: family study of 300000 people with severe mental disorder. Br J Psychiatry 2011; 199: 373-9.

5 MacCabe JH, Lambe MP, Cnattingius S, Sham PC, David AS, Reichenberg A et al. Excellent school performance at age 16 and risk of adult bipolar disorder: national cohort study. Br J Psychiatry 2010; 196: 109-15.

6 MacCabe JH, Lambe MP, Cnattingius S, Torrang A, Bjork C, Sham PC, et al. Scholastic achievement at age 16 and risk of schizophrenia and other psychoses: a national cohort study. Psychol Med 2008; 38: 1133-40.

7 Trotta A, Murray RM, MacCabe JH. Do premorbid and post-onset cognitive functioning differ between schizophrenia and bipolar disorder? A systematic review and meta-analysis. Psychol Med 2015; 45: 381-94.

8 Power RA, Steinberg S, Bjornsdottir G, Rietveld CA, Abdellaoui A, Nivard MM, et al. Polygenic risk scores for schizophrenia and bipolar disorder predict creativity. Nat Neurosci 2015; 18: 953-5.

9 Statistics Sweden MIS 2000:1. Swedish Educational Nomenclature SUN, 2000.

10 Mårdberg B, Carlstedt B. Swedish Enlistment Battery (SEB): construct validity and latent variable estimation of cognitive abilities by the CAT-SEB. Int J Sel Assess 1998; 6: 107-14.

11 World Health Organization (WHO). International Statistical Classification of Diseases and Related Health Problems: 1243. World Health Organisation, 1992.

12 Harper S, Towers-Evans H, MacCabe J. The aetiology of schizophrenia: what have the Swedish Medical Registers taught us. Soc Psychiatry Psychiatr Epidemiol 2015; 50: 1471-9.

13 Jonsson JO, Rudolphi F. Weak performance-strong determination: schoo achievement and educational choice among children of immigrants in Sweden. Eur Sociol Rev 2011; 27: 487-508.

14 Lipsitch M, Tchetgen Tchetgen E, Cohen T. Negative controls: a tool for detecting confounding and bias in observational studies. Epidemiology 2010; 21: 383-8.

15 Vernon PE. The nature-nurture problem in creativity. In Handbook of Creativity. Perspectives on Individual Differences (eds J Glover, R Ronning, C Reynolds): 93-110. Springer, 1989.

16 Post F. Verbal creativity, depression and alcoholism. An investigation of one hundred American and British writers. Br J Psychiatry 1996; 168: 545-55.

17 Di Forti M, Sallis H, Allegri F, Trotta A, Ferraro L, Stilo SA, et al. Daily use, especially of high-potency cannabis, drives the earlier onset of psychosis in cannabis users. Schizophr Bull 2014; 40: 1509-17.

18 Smith I. Psychostimulants and artistic, musical, and literary creativity. Int Rev Neurobiol 2015; 120: 301-26.

19 Kyaga S, Landen M, Boman M, Hultman CM, Langstrom N, Lichtenstein P. Mental illness, suicide and creativity: 40-Year prospective total population study. J Psychiatr Res 2013; 47: 83-90.

20 Frisell T, Öberg S, Kuja-Halkola R, Sjölander A. Sibling comparison designs: bias from non-shared confounders and measurement error. Epidemiology 2012; 23: 713-20. 
21 MacCabe JH, Koupil I, Leon DA. Lifetime reproductive output over two generations in patients with psychosis and their unaffected siblings: the Uppsala 1915-1929 Birth Cohort Multigenerational Study. Psychol Med 2009; 39: 1667-76.

22 Power RA, Kyaga S, Uher R, MacCabe JH, Langstrom N, Landen M, et al. Fecundity of patients with schizophrenia, autism, bipolar disorder, depression, anorexia nervosa, or substance abuse vs their unaffected siblings. JAMA Psychiatry 2013; 70: 22-30.

23 Zimbron J, Stahl D, Hutchinson G, Dazzan P, Morgan K, Doody GA, et al. Premorbid fertility in psychosis: Findings from the AESOP first episode study. Schizophr Res 2014; 156: 168-73.

24 Keller MC, Miller G. Resolving the paradox of common, harmful, heritable mental disorders: which evolutionary genetic models work best? Behav Brain Sci 2006; 29: 385-404; discussion 405.
25 Bergen SE، O'Dushlaine CT, Ripke S, Lee PH, Ruderfer DM, Akterin S, et al. Genome-wide association study in a Swedish population yields support for greater CNV and $\mathrm{MHC}$ involvement in schizophrenia compared with bipolar disorder. Mol Psychiatry 2012; 17: 880-6.

26 Schizophrenia Working Group of the Psychiatric Genomics Consortium. Biological insights from 108 schizophrenia-associated genetic loci. Nature 2014; 511: 421-7.

27 Folley BS, Park S. Verbal creativity and schizotypal personality in relation to prefrontal hemispheric laterality: a behavioral and near-infrared optical imaging study. Schizophr Res 2005; 80: 271-82.

28 Gibson C, Folley BS, Park S. Enhanced divergent thinking and creativity in musicians: a behavioral and near-infrared spectroscopy study. Brain Cogn 2009; 69: 162-9.

\title{
psychiatry in history
}

\section{James Harrington}

\author{
Greg Wilkinson
}

\section{A seventeenth-century cognitive-behavioural self-experiment to test a metamorphic belief}

John Aubrey, FRS (1626-1697), known for his short biographies, relates a 'curious instance'. ${ }^{1}$ James Harrington (1611-1677), political theorist, was arrested and imprisoned for a time. His health deteriorated: 'a living skeleton ... The doctors tried to save his life; and one of these doctors, undertaking to cure his scurvy by decoctions of guaiacum taken in coffee, made him worse, not only in his body but his mind ... He never was himself again'. ${ }^{2}$ Guaiacum was used for syphilis; rheumatism, gout, and respiratory and skin conditions. Whatever the cause of his folly, much later Harrington 'succumbed to an attack of palsy'.

\begin{abstract}
A. ${ }^{0} D^{\text {ni }} .1660$, he was committed prisoner to $y^{e}$ Tower, where he was kept ..... then to Portsey Castle. His durance in these prisons (he being a gent. of a high spirit and hot head) was the procatarctiquea cause of his deliration or madnesse, which was not outrageous, for he would discourse rationally enough, and be very facetious company; but he grew to have a phancy, that his perspiration turned to flies, and some-

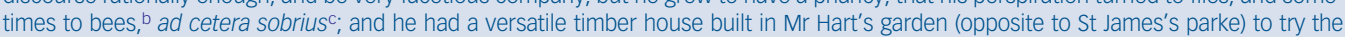
experiment. He would turne it to the sun, and sit towards it; then he had his fox-tayles ${ }^{d}$ there to chase away, and massacre all the flies and bees that were to be found there, and then shutt his chasses e Now this experiment was only to be tryed in warme weather, and some flies would lie so close in the cranies and the cloath ( $w^{\text {th }} \mathrm{w}^{\text {ch }}$ it was hung) that they would not presently shew themselves. A quarter of an hour after, perhaps, a fly, or two, or more might be drawen out of the lurking holes by the warmth, and then he would crye out, 'Doe not you see it apparently that these come from me?' 'Twas the strangest sort of madnesse that ever I found in any one; talke of anything else, his discourse would be very ingeniose and pleasant'.
\end{abstract}

\section{References}

1 Aubrey J. Lives of Eminent Men. Volume II. Part II. Printed for Longman, Hurst, Rees, Orme, and Brown, Pater-Noster Row/Munday and Slatter Oxford: 1813 (pp. 374-5). Researched in The Athenaeum Club Library, London.

2 Dixon WH. Her Majesty's Tower. Volume 4. London: Huest and Blackett, 1871 (p. 40). [archive.org].

\footnotetext{
preceding.

b And, birds: 'or the like. And those about him reported that he talk'd much of good and evil spirits, which made them have frightful apprehensions', according to: J Tolland. The Oceana and Other Works of James Harrington, with an Account of his Life. London: printed for T Beckett and T Cadell, in The Strand, and T Evans, in King Street, Covent Garden, MDCCLXXL. [oll.libertyfund.org]. Tolland adds: 'I grew perfectly amaz'd when I found among his papers the beginning of a little treatise written by himself, wherin (without raillery) he proves 'em to be all mad that thought him so with respect to what he discours'd of nature, which he maintain'd to work mechanically or mathematically, as Bellini, Borelli, Dr. Pitcairne, and other eminent men, have since evidently shewn. It appears there that his pretended visions of angels and devils were nothing else but good or bad animal spirits, and that his flys and bees were only similitudes wherby he us'd to express the various figures and forms of those particles'.

c the rest sensible.

do use as a switch/brush.

ewindows.
} 